\title{
The British Society of Gastroenterology
}

The twenty-ninth Annual General Meeting of the British Society of Gastroenterology was held at the Royal College of Physicians and the Royal College of Surgeons, London, on 7-9 November 1968 with Norman C. Tanner as President (see also page 724).

TROPICAL SPRUE: A STUDY OF SMALL INTESTINAL FUNCTION AND THE CHANGES RESULTING FROM VITAMIN $B_{12}$, FOLATE, AND TETRACYCLINE THERAPY

J. G. BANWELL, S. L. GORBACH, B. CHATTERJEE, AND R. MITRA (The Johns Hopkins University Center, Calcutta) Six patients with tropical sprue in Calcutta, India, have been studied by standard gastroenterological procedure and repetitive intubation with a fine polyvinyl tube system. The latter technique has enabled intestinal fluid samples to be withdrawn from the stomach and all regions of the small intestine for bacteriological culture before measurements of water and electrolyte flux in the ileum and jejunum by a marker perfusion technique. Thirteen subjects from the same community without known gastrointestinal disease have served as controls for the study.

The patients with tropical sprue were found to have bacterial contamination of the upper small intestine and malabsorption of vitamin $B_{12}$, xylose, and fat. Five of the patients had evidence of water and electrolyte secretion into the intestinal lumen when compared with control subjects.

The effects of vitamin $B_{12}$, folate, and tetracycline were studied serially. Radical improvement of fat and vitamin $B_{12}$ absorption and water and electrolyte defects was observed within 48 hours of tetracycline therapy. This was associated with suppression of abnormal small bowel microflora. However, a mild absorptive defect remained despite bacterial clearing, suggesting an underlying mucosal abnormality. The relationship between these features and the changes in intestinal bacterial flora will be discussed.

A ONE-YEAR SURVEY OF THE PREVALENCE OF PSYCHIATRIC ILLNESS IN PATIENTS WITH DISEASE OF THE SMALL INTESTINE

D. P. GOLDBERG (Institute of Psychiatry and St. Thomas' Hospital, London) introduced by B. Creamer. Various suggestions have been made to explain the apparently high incidence of psychiatric morbidity in patients with malabsorption syndromes. Some have implicated deficiencies of specific substances such as folic acid, while others have blamed the distress caused by the associated diarrboea.

In the present study a carefully standardized psychiatric interview of known reliability was carried out on each attendance at the Outpatient Department during the survey year in three groups of patients: those with coeliac syndrome $(n=46)$, those with Crohn's disease $(n=21)$, and those with alactasia $(n=11)$. In addition to the interview each patient completed two psychiatric questionnaires and had a full range of physical investigations. The patients with Crohn's disease and alactasia serve as a control group for the patients with the coeliac syndrome in the sense that, although having small bowel diarrhoea, they do not suffer from generalized malabsorption.

The prevalence of psychiatric illness is shown to be broadly comparable in each of the three diseases, and it is demonstrated that patients with psychiatric illness overrepresent themselves both by being more likely to attend the Outpatient Department and by attending more frequently during the survey year. Emotional distress associated with diarrhoea has not been shown to be an important factor in causing the psychiatric disturbance. Patients with the coeliac syndrome are much more likely to have a family history of psychiatric illness than those in the other groups. The most commonly encountered psychiatric illnesses are shown to be the minor affective syndromes. The previous personalities of the three groups are compared, using information obtained both from the clinical interviews and the questionnaire results.

\section{STEATORRHOEA IN HYPERTHYROIDISM}

W. R. J. MIDDLETON AND G. R. THOMPSON (Department of Medicine, Royal Postgraduate Medical School, London) Steatorrhoea has been observed in six of 10 patients with thyrotoxicosis. Fat absorption was therefore studied in rats fed thyroid extract. The animals developed obvious hyperthyroidism and their faecal fat excretion on a daily intake of $3 \mathrm{~g}$ dietary fat was $296 \mathrm{mg} /$ day, compared with $72 \mathrm{mg} /$ day in controls $(P<0.001)$. The excretion of ${ }^{14} \mathrm{C}$-triolein after intragastric administration in $0.5 \mathrm{ml}$ olive oil was $25.3 \%$ in controls and $49.9 \%$ in hyperthyroid rats $(\mathrm{P}<0.001)$; the excretion of ${ }^{14} \mathrm{C}$-oleic acio was $23.4 \%$ and $44.9 \%$ respectively $(P<0.001)$. These results showed that hyperthyroid rats malabsorbed both triglyceride and fatty acid.

The absorption of ${ }^{14} \mathrm{C}$-linoleic acid, administered intraduodenally in the form of either mixed micelles or as an emulsion, did not differ significantly in control and hyperthyroid rats. Studies in bile fistula rats showed that the total concentration of conjugated bile acids was similar in both groups, although the ratio trihydroxy:dihydroxy bile acids was nearly $2: 1$ in controls but decreased to $0 \cdot 6: 1$ in hyperthyroid rats.

Finally, the rate of gastric emptying and intestinal transit time was measured with ${ }^{14} \mathrm{C}$-triolein. At 15 minutes after intragastric administration $78.6 \%$ of the radioactivity remained in the stomach of control rats but only 
$11.7 \%$ in the hyperthyroid rats. At 45 minutes $15.7 \%$ was recovered from the distal small intestinal wall and contents in the controls, compared with $64.1 \%$ in the hyperthyroid animals. These findings suggest that steatorrhoea in hyperthyroidism is not due to a primary defect of pancreatic, biliary, or mucosal function but is associated with a markedly enhanced rate of gastrointestinal transit.

\section{MEDULLARY CARCINOMA OF THE THYROID ASSOCIATED WITH} DIARRHOEA: REPORT OF FIVE CASES

J. J. BERNIER, J. C. RAMBAUD, D. CATTAN, AND A. PROST (Hôpital Saint-Lazare, Paris) introduced by B. Julien. Diarrhoea associated with five cases of medullary carcinoma of the thyroid ${ }^{\mathbf{1}, 2}$ leads mainly to excessive losses of water and electrolytes. Steatorrhoea was mild or absent, and intestinal absorption of sugar and vitamin $B_{12}$ was normal; the histological appearance of the jejunal mucosa was normal or subnormal. This water and sodium diarrhoea seems to be linked to a sometimes considerable increase in the rate of transit through the small intestine and colon, and may be relieved by codeine or codethyline. The frequent increase in the maximum blood sugar during an oral tolerance test should not be interpreted as evidence of a paradiabetic condition, which might explain the motor disorder. In fact, the intravenous glucose tolerance test is normal and the excessive rise in blood sugar after administration by mouth seems to be the consequence of an increased rate of transit through the small intestine.

The link between the tumour and the disordered motility seems definite in view of certain cases where removal of the tumour caused immediate disappearance of the diarrhoea. These cases suggest the presence of a humoral factor. Production by the tumour of serotonin or other derivatives of tryptophan, or of kallicrein, which activates bradykinin, is not constant. An increased secretion of prostaglandins is possible, but requires further confirmation.

The only hormone substance, secretion of which seems to be definitely increased in medullary carcinoma of the thyroid, is thyrocalcitonin, but this hormone does not seem to have any effect on motor activity of the digestive tract.

\footnotetext{
${ }^{1}$ Bernier, J. J., Bouvry, M., Cattan, D., and Prost, A. (1966). Diarrhée motrice par cancer médullaire thyroldien. Nouvelle entité anatomo-clinique. Bull. Mén. Soc. Méd. Hôp. Paris, 117, 1191-1197.

${ }^{2}$ Williams, E. D. (1966). Histogenesis of medullary carcinoma of thyroid. J. clin. Path., 19, 114-118.
}

\section{CHANGES IN THE MYENTERIC PLEXUS IN} PSEUDO-OBSTRUCTION

BARBARA SMITH (St. Bartholomew's Hospital, London) introduced by A. M. Dawson. A distinctive lesion was found in the myenteric plexus of two patients with unexplained pseudo-obstruction of the bowel. One presented with recurrent small bowel obstruction (Naish, Capper, and Brown, $1960^{1}$; McClelland, Lewis, and Naish, $1962^{2}$ ) and the other with intractable constipation. There was thickening of all muscle coats in the affected bowel but this occurred particularly in the inner coat. Routine histological techniques showed minimal or debatable abnormalities of the myenteric plexus but changes were obvious in silver preparation tissue cut in the plane of the plexus. The plexus showed loss of neurones and axons, while the remaining neurones were frequently swollen and some had bizarre shapes, and there was marked proliferation of the Schwann cells in response to axonal loss. These changes differ from those hitherto found in Hirschsprung's disease and other disorders of the myenteric plexus with which they will be contrasted and compared; they probably account for muscular disorder of the bowel.

${ }^{2}$ Naish, J. M., Capper, W. M., and Brown, N. J. (1960). Gut, 1, 62. 'McClelland, H. A., Lewis, M. J., and Naish, J. M. (1962). Ibid., 3, 142.

\section{EFFECT OF PROSTAGLANDINS ON INTESTINAL MOTILITY}

G. B. SCHOLES, K. G. ELEY, AND A. BENNETT (Department of Surgery, King's College Hospital Medical School, London) Prostaglandins, which are potent biologically active lipids widely distributed in mammalian tissues, have recently been found in the alimentary tract of man and other animals (Bennett, Murray, and Wyllie, 1968). ${ }^{1}$ We have studied first the effects of prostaglandins $E_{1}$ and $E_{2}$ on strips of human and guinea-pig isolated ileum, and secondly their action on guinea-pig intestinal activity both in vitro and in vivo. The prostaglandins caused contractions of the isolated longitudinal muscle in both species. In contrast, the circular muscle strips were generally inhibited. Peristalsis in isolated guinea-pig ileum was affected similarly, but the major effects were inhibition of circular muscle contraction and a diminution of propulsion of fluid through the gut lumen. In anaesthetized guinea-pigs, serosal application of prostaglandin always contracted the longitudinal muscle, whereas injection into the blood stream caused either contraction or relaxation. The effect of blood-borne prostaglandin on the intraluminal pressure of the intestine was also variable: sometimes the pressure increased and sometimes it remained unchanged. This finding, together with the facts that E-type prostaglandins cause hypotension and are rapidly cleared by the liver and lungs, makes it unlikely that circulating E-type prostaglandins are normally involved in gastrointestinal motility. Our evidence indicates, however, that prostaglandin released locally within the gut wall may have such a role.

'Bennett, A., Murray, J. G., and Wyllie, J. H. (1968). Brit. J. Pharmacol., 32, 339-349.

PHARMACOLOGY AND HISTOPATHOLOGY OF THE CARDIAC SPHINCTER IN ACHALASIA

J. J. MISIEWICZ, SHEILA L. WALLER, P. P. ANTHONY, AND J. W. P. GUMMER (M.R.C. Gastroenterology Research Unit, Department of Histopathology and Department of Surgery, Central Middlesex Hospital, London) Achalasia of the cardia is associated with degeneration of the myenteric nervous plexus, but doubt exists whether the cardiac sphincter itself is denervated.1,2 Earlier in vitro observations on human oesophageal muscle ${ }^{2}$ need to be interpreted in terms of $\alpha$ - and $\beta$-adrenergic receptors. 
In this study, in vitro pharmacological responses of 18 muscle strips from the cardiac sphincter of 16 patients with achalasia have been compared with responses of 20 sphincteric muscle strips from 13 patients without achalasia. The number of ganglion cells in the muscle strips from both groups was assessed by a semiquantitative histological technique, and the pharmacological and histological data were correlated.

The pharmacological results indicate that both $\alpha$ - and $\beta$-adrenergic receptors are present in both muscle layers of the sphincter. The $\alpha$-receptors mediate contractions, whilst the $\beta$-receptors mediate relaxations. These responses resemble those found in other human alimentary sphincters.

The intrinsic innervation of the circular muscle in the non-achalasic sphincter contains inhibitory neurones, acting through $\beta$-adrenergic receptors. This differs from the innervation of the longitudinal layer which possesses both $\beta$-adrenergic relaxant activity and cholinergic contractile activity. In achalasia, the $\beta$-adrenergic inhibitory activity was lost in both layers of the cardiac sphincter.

Histological studies show that ganglion cells were absent from the cardiac sphincter in almost all the patients with achalasia who were studied; if present, they were morphologically abnormal. The myenteric plexus of nerves though present, showed marked abnormalities.

These data suggest that failure of the achalasic cardiac sphincter to relax is due to denervation and loss of $\beta$-adrenergic inhibitory activity.

${ }^{1}$ Hurst, A. F., and Rake, G. W. (1929-30). Quart. J. Med., 23, 491.

'Trounce, J. R., Deuchar, D. C., Kauntze, R., and Thomas, G. A. (1957). Quart. J. Med., (N.S.), 26, 433.

TREATMENT OF ACHALASIA BY PNEUMATIC DILATATION OF THE CARDIA

JOHN R. BENNETT, E. BARZAGA, T. R. HENDRIX, AND C. I. SIEGEL (Johns Hopkins Hospital, Baltimore, U.S.A.) Forceful dilatation of the cardia by the Hurst-Tucker pneumatic dilator under fluoroscopic control has been used to treat 51 of the 77 achalasia patients seen at the Johns Hopkins Hospital, Baltimore, in the last 11 years. The instrument is a mercury-filled rubber tube with a distal inflatable radioopaque bag. A single dilatation, with only local pharyngeal anaesthesia, was carried out on each patient.

Good immediate results were obtained in 48 patients, most of whom were swallowing without difficulty within 24 hours of the procedure. Failures were two patients with carcinoma of the gastrooesophageal junction (undetected before dilatation) and one in whom the dilator would not enter the cardia. Morbidity was small; the oesophagus was perforated twice without serious complications. The mean hospital stay was $8 \cdot 3$ days and the average interval between dilatation and discharge from hospital was 3.5 days.

Twenty-one patients have a good result two years or more after their dilatation. Seven developed recurrent stenosis but five of these have had further successful dilatations. Two patients are considered to have a poor result due to gastrooesophageal reflux. Eighteen patients, followed for less than two years, were symptom-free when last seen, giving an overall rate of $92.5 \%$.

The advantages of pneumatic dilatation over cardiomyotomy are: (1) avoidance of surgery, (2) low incidence of subsequent gastrooesophageal reflux, (3) short hospital stay, (4) the procedure can easily be repeated if results are unsatisfactory.

STUDIES ON THE SUBCELLULAR LOCALIZATION OF PEPTIDASES IN INTESTINAL MUCOSAE

T. J. PETERS (M.R.C. Intestinal Malabsorption Research Group, Royal Postgraduate Medical School, London) introduced by C. С. воотн. It is well established that the final stages of polysaccharide digestion are brought about by oligosaccharidases present in the brush border of the intestinal cell. Although the evidence suggests that there is relatively little peptidase activity in the lumen of the small intestine, it is uncertain whether the final stages of protein digestion occur at the brush border of the enterocyte. Rhodes, Eichholtz, and Crane (1967) 1 , however, have found dipeptidase activity in microvillous membranes derived from hamster intestinal brush borders.

In this paper the quantitative subcellular localization of various tripeptidases, dipeptidases, and amidases will be described. An automated kinetic assay for peptidases was developed. Guinea-pig mucosa was fractionated by a modification of the method of Eichholtz and Crane $(1965)^{2}$ and by the method of Hübscher, West, and Brindley (1967). ${ }^{3}$ The distribution of peptidase activity in the subcellular fractions (brush borders, mitochondria/ lysosomes, microsomes, and cell sap), using a variety of substrates, was determined. It was found that most of the dipeptidase activity was present in the soluble 'cell sap' fraction and little was localized in the brush borders. Approximately $20 \%$ of tripeptidase activity, however, was recovered from the brush border area. The implications of these findings in the physiology of protein absorption will be discussed.

${ }^{1}$ Rhodes, J. B., Eichholtz, A., and Crane, R. K. (1967). Biochim. biophys. Acta (Aust.), 135, 959-65.

${ }^{2}$ Eichholtz, A., and Crane, R. K. (1965). J. Cell Biol., 26, 687-91.

${ }^{3}$ Hübscher, G., West, Gwen R., and Brindley, D. N. (1967). Biochem. J., 97, 629-42.

A STUDY OF THE MUCOSAL STRUCTURE OF THE SMALL INTESTINE USING THE SCANNING ELECTRON MICROSCOPE

M. N. MARSH, J. A. SWIFT, E. D. WILliams (Royal Postgraduate Medical School, London, and Unilever Research Laboratories) introduced by G. NEALE. The scanning electron microscope (S.E.M.) (Stereoscan, Cambridge Instrument Co., England), has been used to study the mucosal surface of the small bowel of control subjects and of patients with coeliac disease. This instrument is capable of magnifying up to $\times 10,000$, resolving structures of $0.05 \mu$ diameter, and has great depth of field focus. Samples of intestinal mucosa can be viewed at any angle, and by tilting the specimen through a small angle, stereo-fair electron micrographs can be obtained which facilitate the interpretation of the surface structure. It is 
also possible to examine the face of a sectioned specimen of intestinal mucosa.

Specimens of fresh jejunal mucosa were washed with saline, fixed in chilled glutaraldehyde, and stored in phosphate-sucrose buffer at $4^{\circ} \mathrm{C}$. When required for inspection specimens were washed in water, freeze dried, and coated with thin films of carbon $\left(100^{\circ} \mathrm{A}\right)$ and silver $\left(500^{\circ} \mathrm{A}\right)$. They were then viewed in a Stereoscan, operated at an accelerating potential of $20 \mathrm{KV}$ and high resolution photographs were taken on Ilford FP3 film.

In specimens of jejunal mucosa from control subjects we have examined the structure of villi and have shown that they are indented with irregular corrugations, into which goblet cells appear to open. The boundaries of individual surface cells can be clearly discerned together with the orifices of goblet cells. At high magnification microvilli are easily resolved. These appear as ciosely packed rod-shaped structures about $\mathbf{0} \cdot 2 \mu$ diameter.

Mucosal specimens from patients with the coeliac syndrome show a widely variable surface structure. Patches of microvilli are seen particularly on cells around the orifices of crypts, even on the surface of a 'flat' mucosa. Cells in adjacent areas, however, may be completely devoid of microvilli.

In this paper we demonstrate that the scanning electron microscope can add a third dimension to the study of the cellular structure of the intestinal mucosa.

\section{POSITIONING OF NASOGASTRIC TUBES WITHOUT FLUOROSCOPY}

M. A. HASSAN AND M. HOBSLEY (The Middlesex Hospital, London) It is widely held that the position of the tube within the stomach affects the results of gastric secretion studies, and in consequence radiological checking of the position of the tube is recommended. The validity of this concept has been investigated.

In 43 subjects, a nasogastric tube was passed blindly. Its position was adjusted until a free recovery of at least $80 \%$ of an instilled sample $(20 \mathrm{ml})$ of water was obtained. Subsequent fluoroscopy demonstrated the tip of the tube definitely within the stomach in all subjects.

In seven early studies, tubes were readjusted during screening so as to lie in the 'optimal' sites, but in the remaining 36 the position achieved by the recovery test was accepted, whether radiologically 'optimal' (18 cases), or not (18 cases).

In the 36 subjects, gastric secretion studies were performed using a constant intravenous infusion of histamine acid phosphate $0.04 \mathrm{mg} / \mathrm{kg} /$ hour. Completeness of recovery of gastric secretion was assessed by simultaneous instillation of phenol red and its measurement in aspirated samples (Hobsley and Silen, 1966) ${ }^{\mathbf{1}}$. The average recovery rate was $81.5 \%$ in the group with tubes in the 'optimal' position, $84.7 \%$ in the group with tubes in apparently unsatisfactory position.

We conclude that (a) screening is unnecessary provided a simple recovery test is used; and (b) provided that the tip of the nasogastric tube is within the stomach, there is no 'optimal' position.

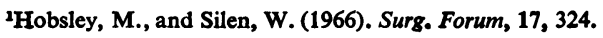

GASTRIC ACID SECRETION STIMULATED BY EXTREMELY LOW DOSES OF PENTAGASTRIN

M. C. MASON AND G. R. GILES (University Department of Surgery, Leeds) It has been suggested that the acidsecreting cells in patients with duodenal ulceration show no difference in responsiveness to stimulation when compared with normal individuals. ${ }^{1}$ However, this might not be so when very small doses of a commercial gastrin are used. ${ }^{2}$ The existence of differing characteristics at the extreme lower range of the dose response curve following a continuous pentagastrin infusion is confirmed for duodenal ulcer subjects by this work.

A test of acid secretion has been developed which utilizes this difference in behaviour. Pentagastrin, made up in saline, is infused at a dose of $0.000625 \mu \mathrm{g} / \mathrm{kg} / \mathrm{hr}$ and the resulting degree of stimulation is calculated in relation to the 'maximal' response evoked from an infusion at $1.2 \mu \mathrm{g} / \mathrm{kg} / \mathrm{hr}^{3} \mathrm{~A}$ positive response has been defined.

Studies have been performed on 17 patients with duodenal ulcer, eight with gastric ulcers, 11 normal volunteers, and in 16 with dyspepsia but negative radiological findings. Significant stimulation was shown only by the duodenal ulcer group whilst those with an apparently non-ulcer dyspepsia occupied a somewhat intermediate position.

The role of this test, which combines an assessment of the behaviour of the human stomach with a measure of its parietal cell population, is discussed with particular reference to its potential usefulness in clinical investigation and treatment.

${ }^{1}$ Wormsley, K. G., and Mahoney, M. P. (1967). Brit. med. J., $1,278$. ${ }^{2}$ Giles, G. R., and Clark, C. G. (1967). Brit. J. Surg., 54, 834.

${ }^{3}$ Mason, M. C., Giles, G. R., and Clark, C. G. (1968). Gut, in press.

'IN VITRO' ASSAY OF BILIRUBIN-UDP GLUCURONYL TRANSFERASE ACTIVITY IN THE LIVER OF PATIENTS WITH GILBERT'S SYNDROME AND A VARIETY OF HEPATIC DISORDERS

M. BLACK AND B. H. BILliNG (Department of Medicine, Royal Free Hospital, London) introduced by S. Sherlock. Investigation into patients with persistent non-haemolytic unconjugated hyperbilirubinaemia has been hampered by the lack of a satisfactory method of assaying the hepatic conjugating enzyme, bilirubin-UDP glucuronyl transferase. Methods do exist which enable an assay to be made on tissue obtained at laparotomy, but in general, they have been too insensitive to provide a satisfactory result with lesser amounts of tissue, such as is available following percutaneous needle biopsy of the liver.

Van Roy and Heirwegh (1968) ${ }^{1}$ have recently introduced a new method for assaying the specific enzyme in which diazotisation of the reaction products of the primary incubation is performed with ethylanthranilate at an acid $p H$. It can be shown that in the presence of an excess of unconjugated bilirubin, the colour developed at the $p \mathrm{H}$ used is proportional only to the amount of conjugated bilirubin present at the end of the incubation procedure. We have confirmed the specificity of this method in animal experiments and have been able to 
adapt it so that assays can be carried out on tissue obtained from needle biopsy of the liver, as well as from laparotomy specimens. Our preliminary observations in man have enabled us to define a fairly narrow range of enzyme activity in normal subjects. In patients with Gilbert's syndrome, in which there may be only slight elevation of the serum bilirubin at the time of the assay, enzyme activity is significantly reduced. In all hepatic disorders studied, with the exception of two patients with Wilson's disease, the enzyme is present in normal or increased amounts.

'Van Roy, F. P., and Heirwegh, K. P. H. (1968). Biochem. J., 107, 507.

DELAYED HYPERSENSITIVITY IN PRIMARY BILIARY CIRRHOSIS

R. A. FOX, P. J. SCHEUER, S. SHERLOCK, O. SHARMA, AND D. G. JAMES (Departments of Medicine, the Royal Free Hospital and the Royal Northern Hospital, London) Fifty-one patients with primary biliary cirrhosis have been studied and granulomata have been found within the liver in 29. The Kveim test for sarcoidosis was negative. A granulomatous response appears to be an essential prerequisite for the manifestation of cellular immunity, and a granuloma may also be the site of a chronic delayed hypersensitivity response. These results suggest a disturbance of delayed hypersensitivity in patients with primary biliary cirrhosis.

The induction of delayed hypersensitivity has been studied in various ways. A significant proportion of these patients do not become sensitized after contact with dinitrochlorobenzene. Compared with controls a significant number show no response to intradermal injections of purified protein derivative and Candida. This anergy is also reflected in the in vitro lymphocyte transformation response following exposure to phytohaemagglutinin. This was greatly depressed in patients with primary biliary cirrhosis compared with those suffering from other forms of cholestasis. There was no correlation between the in vitro lymphocyte transformation response and the antimitochondrial antibody titre, and the degree of depression does not appear to be related to the elevation of the serum alkaline phosphatase or bilirubin levels.

It is concluded that delayed hypersensitivity is impaired in a significant number of patients with primary biliary cirrhosis.

EFFECTS OF TRYPSIN INHIBITORS ON THE ACINAR CELLS OF THE RAT PANCREAS

R. N. MELMED AND I. A. D. BOUChIER (Medical Unit, Royal Free Hospital, London) In keeping with the observations of other workers pancreatic enlargement has been produced by supplementing the diet of rats with raw soybean flour. Heated soybean flour has no such effect. The pancreas appears normal on microscopic examination. The use of low levels of dietary supplements of purified trypsin inhibitor from soybean, ovomucoid, and bovine pancreas is associated with a similar pancreatic enlargement. There is a striking increase in amylase capacity and specific activity in these glands compared to control animals fed on standard laboratory diet.
The ability of the pancreas to respond in this manner is uninfluenced by prior vagotomy. Studies in neonatal rats born of mothers who had been fed dietary supplements of raw soybean meal throughout gestation suggest that this potential of the trypsin inhibitor to stimulate pancreatic digestive enzyme synthesis may be transmitted transplacentally. The results of pancreatic fistula studies in rats will be presented.

The role of the naturally occurring trypsin inhibitors in pancreatic physiology will be discussed. It is postulated that the trypsin inhibitors are potent releasors of a trophic substance from the intestinal mucosa which acts upon pancreatic acinar cells.

\section{DISAPPOINTMENTS OF PANCREATIC SCINTISCANNING}

M. BAUM, C. T. HOWE, S. B. OSBORNE, AND N. STRICKLAND (Departments of Surgery, Medical Physics \& Radiology, King's College Hospital, London) Forty patients with suspected pancreatic disease have been investigated by scintiscanning the abdomen after an injection of selenomethionine according to the method of Blau and Bender (1962). ${ }^{1}$ Our object was to decide the value of this technique in the routine clinical management of such patients. The scans were reviewed by a panel of four, each unaware of the final diagnosis, and their interpretations were compared with the correct answer.

The conclusions were as follows:

1 It was not possible to interpret 15 of the pancreatic scans when examined by themselves, due to overlap by the liver or failure to demonstrate the pancreas.

2 Eight of these patients had also had a liver scan. Despite this six of the pancreatic scans were still not interpretable but in two others the liver scan did make it possible to interpret a previously unintelligible pancreatic scan.

3 In 16 patients the head of the pancreas had been localized by hypotonic duodenography or simultaneous duodenal scanning (Baum and Howe, 1968). ${ }^{2}$ Four of these pancreatic scans were unintelligible.

4 In the majority of patients the management was guided by other considerations, but in three laparotomy was undertaken largely because of an 'abnormal' pancreatic scan and no abnormality was found.

5 To date, pancreatic scintiscanning, as a routine investigation, does not give sufficiently reliable information to play a part in clinical management of patients with suspected pancreatic disease.

${ }^{1}$ Blau, M., and Bender, M. (1962). Radiology, 78, 974.

${ }^{2}$ Baum, M., and Howe, C. T. (1968). Amer. J. Surg., 115, 519.

\section{VOLVULUS OF THE INTESTINE IN IRAN}

FARROKH SAIDI (Pahlavi University, Shiraz, Iran) introduced by A. E. Read. Volvulus of the large and small bowel has been found to have a remarkably high incidence in the adult indigenous population of southern Iran, and is the most common cause of intestinal obstruction in this region. Experience with over 40 cases of primary small bowel volvulus (not due to adhesions, etc.) has shown this to be a distinct clinical entity.

The equally high incidence of sigmoid volvulus in the 
same population is in sharp contrast to the paucity, if not total absence, of diverticular disease in this area. Volvulus of the caecum is also more common than is seen in the west.

Dietary factors and bowel habits of patients and the population at risk have been investigated in search of possible explanation of the geographical discrepancy in the incidence of this intestinal disorder. Postmortem measurements of intestinal and mesenteric lengths have also been carried out, showing a disproportionate ratio of bowel length to mesenteric width, suggesting a congenital rather than acquired basis for volvulus of bowel.

Diagnostic and therapeutic measures adopted for small bowel volvulus as well as operative results to be expected have become defined.

Follow-up studies on a number of cases with volvulus of the large bowel have brought out the relative merits of different modes of treatment for this condition.

\section{CANCER OF THE COLON AND RECTUM AND ITS RESPONSE TO} TREATMENT

G. SLANEY, J. A. WATERHOUSE, AND J. POWELl (Birmingham) This is a study of 12,494 cases of cancer of the colon and rectum treated in the Birmingham region during the period 1950-61. The population of this region is approximately five millions and thus comprises about one-tenth of that of the United Kingdom.

The crude overall five-year survival rate of the 12,494 cases was $21.1 \%$ and in $22.4 \%$ of the patients no treatment at all was possible. The crude 10 -year survival rate for almost 4,500 cases was $14.0 \%$.

In patients treated by radical surgery the crude fiveyear survival rates were $42.3 \%$ for colon and $39.8 \%$ for rectum. The patients with the longest history had the best survival rate in each group and the site of the primary had no influence on the duration of symptoms when the patients were first seen.

These low five-year survival rates are most unsatisfactory and indicate that current methods of management of large bowel cancer require urgent reappraisal.

\section{LIVER AND ORAL CARBOHYDRATE TOLERANCE}

NEIL MCINTYRE, D. TURNER, AND DEREK HOLDSWORTH (Royal Free Hospital and St. Bartholomew's Hospital, London) Peripheral blood levels of glucose or fructose are much lower after intrajejunal than after intravenous administration. Differences in absorption cannot account for this, and the cause must therefore lie in increased metabolism either in the liver or elsewhere.

With fructose, significant hepatic extraction from portal blood has been confirmed by two types of experiment. In anaesthetized dogs blood levels of fructose were much lower when fructose was infused into the portal vein than when infused into a peripheral vein. In man blood levels after oral fructose were consistently higher after portacaval anastomosis than before operation.

Glucose tolerance, however, was almost identical in anaesthetized dogs whether glucose was infused into the portal vein or on a second occasion into a peripheral vein. Furthermore six patients studied before and after portacaval anastomosis showed no change in oral glucose tolerance. In contrast to what might be expected (Samols and Holdsworth, 1968) ${ }^{1}$ the plasma insulin response was no greater after operation. These findings indicate that the widespread assumption that the superiority of oral over intravenous glucose tolerance is due to hepatic glucose removal is probably incorrect. Stimulation of insulin secretion by a jejunal hormone (McIntyre, Holdsworth, and Turner, 1965) ${ }^{2}$ is a more likely cause.

${ }^{1}$ Samols, E., and Holdsworth, C. D. (1968). Disturbances in carbohydrate metabolism: Liver disease in Carbohydrate Metabolism and its Disorders, edited by Dickens, F., Randle, P. J., and Whelan, W. J. Academic Press London.

${ }^{2}$ McIntyre, N., Holdsworth, C. D., and Turner, D. (1965). J. clin. Endocr., 25, 1317.

EXPERIENCE WITH EXTRACORPOREAL PIG LIVER PERFUSION IN THE TREATMENT OF HEPATIC COMA

G. M. ABOUNA (Department of Surgery, University of Newcastle upon Tyne) introduced by I. D. A. Johnston. The mortality from hepatic coma, due to acute hepatic necrosis, treated by conventional methods is high. Recently, two new methods of treatment have been tried. Exchange blood transfusion, first described by Berger, Liversage, Chalmers, Graham, McGoldrich, and Stohlman (1966), ${ }^{1}$ is simple to carry out but places great demands on a blood transfusion service. Extracorporeal pig liver perfusion, described by Eiseman, Liem, and Raffucci (1965), ${ }^{2}$ requires complicated equipment but is physiologically and therapeutically rational.

A technique of prolonged extracorporeal pig liver perfusion with human blood has been developed (Abouna, $1968)^{3}$ and tried experimentally in the resuscitation of animals with acute liver failure when its therapeutic value was confirmed. This technique has now been used to provide temporary hepatic support for four patients (aged 6 to 47 years) in terminal stages of hepatic failure, all of whom had failed to respond to conventional medical treatment. Viral hepatitis was the cause of coma in two patients. In one patient the cause was toxic hepatitis with septicaemia and gas gangrene, and in the fourth the coma developed rapidly following a gastrointestinal haemorrhage in a patient with cirrhosis. Three of the patients, in addition to hepatic coma, had renal failure, respiratory infection, and pulmonary oedema, and were being maintained with artificial ventilation and peritoneal dialysis. These patients were connected to the extracorporeal liver for periods of six to 10 hours by means of a silastic AV shunt with regional heparinization, on two occasions at 48-hour intervals. Perfusions were followed by lightening of coma and improvement in the general condition in three patients. The fourth patient, who had been free from extrahepatic complications at the time of perfusion, recovered consciousness completely but died four days later from massive gastrointestinal haemorrhage. In all patients there was a marked fall in the levels of serum bilirubin, ammonia and alkaline phosphatase, with an appreciable rise in the levels of prothrombin and fibrinogen after each perfusion. Immunological studies in these patients failed to demonstrate an antibody to porcine protein. 
The technique employed and the apparatus used will be described in detail, and the clinical and biochemical results obtained after perfusion in these patients will be presented.

'Berger, R. L., Liversage, R. M., Chalmers, T. C., Graham, J. H., McGoldrich, D. M., and Stohlman, F. (1966). New Engl. J. Med., 274, 497.

'Eiseman, B., Liem, D. S., and Raffucci, F. (1965). Ann. Surg., 162, 329 .

${ }^{3}$ Abouna, G. M. (1968). Brit. J. Surg., in the press.

EFFECTS OF BICARBONATE ON INTESTINAL ABSORPTION

G. E. SLADEN, D. S. PARSONS, AND J. DUPRE (Department of Biochemistry, University of Oxford, and St. Bartholomew's Hospital, London) introduced by A. M. Dawson. It has recently been shown that bicarbonate ions have a stimulant effect on the absorption of sodium and water by the normal human jejunum. ${ }^{1}$ This effect is quantitatively comparable to the maximum effect produced by glucose and is not due to an alteration of $p \mathrm{H}$. This has now been studied, in more detail, using preparations of rat intestine in vitro. Krebs-Ringer solution containing either bicarbonate or phosphate and $500 \mathrm{mg} \%$ glucose has been recirculated through the intestinal lumen and absorbed fluid collected as 'sweat' on the serosal side, which is bathed in liquid paraffin. The jejunum and ileum have been studied separately at $p \mathrm{H} 7.4$ and the effect at other $p \mathrm{Hs}$ has been studied in the jejunum only. Bicarbonate ions significantly stimulate the transport of water and sodium by the jejunum, but the magnitude of the effect is $p \mathrm{H}$ dependent. No stimulant effect of bicarbonate was found in the ileum and glucose translocation at both sites was unaffected.

This effect is important for three reasons: (1) The composition of the buffered solution must be considered in in vivo and in vitro studies of fluid and electrolyte absorption. For example, it may explain some conflicting evidence about the role of glucose in fluid transport. ${ }^{2}$ (2) This may represent an important physiological stimulus for sodium absorption. (3) It may be relevant to the recently reported observations that glucosebicarbonate solutions can be absorbed in cholera and will greatly reduce the requirements for intravenous fluids. ${ }^{3}$

ISladen, G. E., and Dawson, A. M. (1968). Effect of bicarbonate on sodium absorption by the human jejunum. Nature (Lond.), 218, 267-268.

${ }^{2}$ Wilson, T. H. (1956). Fluid movement across the wall of the small intestine in vitro. Amer. J. Physiol., 187, 244-246.

${ }^{3}$ Nalin, D. R., Cash, R. A., Islam, R., Molla, M. and Phillips, R. A. (1968). Oral maintenance therapy for cholera in adults. Lancet, 2, 370-372.

EFFECT OF BILE SALTS ON INTESTINAL FATTY ACID ABSORPTION AND ESTERIFICATION IN THE RAT

M. CLARK AND J. SENIOR (Philadelphia General Hospital, Philadelphia, Pa., USA) introduced by J. Dow. In patients with blind loops and steatorrhoea an overgrowth of bacteria may be found in the upper small gut. These bacteria can dehydroxylate and deconjugate bile salts, but whether the steatorrhoea found is due to the presence of free bile acids or to a diminished concentration of conjugated bile salts is uncertain. We studied in the rat the effect of bile salts on fatty acid esterification in vivo, and on fatty acid absorption and esterification in vitro. In the everted intestinal sac the optimal rate of esterification of $\mathbf{C}^{\mathbf{1 4}}$-palmitate in micellar solution in phosphate buffer at $p H 6.5$ was achieved with 10 to $20 \mathrm{mM}$ sodium taurocholate; reduction in the concentration of taurocholate decreased the amount of fatty acid esterified. Chenodeoxycholate or deoxycholate in a concentration of $1 \mathrm{mM}$ added to micellar solutions of $\mathrm{C}^{\mathbf{1 4}}$-palmitate and $15 \mathrm{mM}$ taurocholate severely inhibited fatty acid esterification. Cholic acid showed comparable inhibition of esterification only at $10 \mathrm{mM}$ concentration.

Intraduodenal perfusion of micellar solutions of $\mathbf{C}^{\mathbf{1 4}}$ palmitate in $15 \mathrm{mM}$ taurocholate over 10 hours to unanaesthetized rats produced a steady state of lipid absorption into lymph. Addition of up to $5 \mathrm{mM}$ deoxycholate to this micellar solution did not inhibit either fatty acid absorption into lymph or esterification into triglycerides. Reduction, however, of the concentration of taurocholate to below $10 \mathrm{mM}$ reduced the amount of palmitate absorbed; the percentage of fatty acid converted to triglycerides remained constant. These results support the idea that in the blind loop syndrome the steatorrhoea is due to a decrease in conjugated bile salts rather than a toxic effect of free bile salts.

FATTY ACIDS IN THE LUMEN OF THE SMALL INTESTINE FOLLOWING A LIPID-CONTAINING MEAL

M. A. EASTWOOD (University Department of Therapeutics, Royal Infirmary, Edinburgh) It is becoming apparent that, during lipid absorption, there is a complex interplay between the constituents of emulsions and micelles and a fibrous phase of nutritional origin. Bile salts and, possibly, fatty acids are adsorbed onto lignin present in vegetable fibre (Eastwood and Hamilton, 1968). ${ }^{1}$ It is important, therefore, to know what changes occur in the relative concentrations of fatty acids along the small intestine following the ingestion of a fatty meal. In this way one can anticipate the effect of a meal containing vegetable fibre on the fatty acids in the intestinal lumen.

Volunteers with no history of gastrointestinal abnormalities were intubated using a transintestinal technique (Blankenhorn, Hirsch, and Ahrens, 1955). ${ }^{2}$ A constituted dried milk meal of known lipid composition was given. Intestinal contents were aspirated at levels varying from the duodenum to $225 \mathrm{~cm}$ from the nose. The lipids were extracted, chromatographed using silicic acid chromatography, and estimated. The free and conjugated fatty acids were methylated and analysed using gas liquid chromatography.

In other experiments, gastric contents were aspirated after one, two, and three hours post-prandially.

It was shown that there is some hydrolysis of the milk triglycerides in the gastric phase of ingestion with the release of some free fatty acids.

There was the expected rapid absorption of glycerides from the upper small intestine. The relative proportions of fatty acids, both as glycerides and as the free fatty acids, remain remarkably constant in the intestinal lumen, even as far along the small intestine as 225 to $260 \mathrm{~cm}$. 
The significance of this in relation to adsorption to solid components of the intestinal contents is discussed.

${ }^{1}$ Eastwood, M. A., and Hamilton, Desiree (1968). Biochim. biophys. Acta (Aust.), 152, 165.

${ }^{2} B l a n k e n h o r n$, D. H., Hirsch, J., and Ahrens, E. A. (1955). Proc. Soc. exp. Biol. (N.Y.), 88, 356.

THE 'SPEAKING STOMACH' SYNDROME

D. A. W. EDWARDS (M.R.C. Dept. of Clinical Research, University College Hospital Medical School, London) The 'speaking stomach' syndrome consists of bouts, lasting minutes or hours, of a rhythmic noise from the abdomen synchronous with breathing, with a long gurgle during inspiration and a short one in expiration. The noise is easily heard across a room and is a source of great social embarrassment and distress. Only one of three subjects could produce or stop the noise deliberately, but it started and stopped apparently spontaneously in all three.

The noise is produced at the gas-liquid interface in a long J-shaped stomach in the upright position. The major and possibly only necessary factor in noise production is an abrupt and excessive downward movement of the left hemidiaphragm which moves the gas-liquid-stomach wall interface fast enough to create noise during descent and ascent. This may be a primary disorder of the diaphragm or its motor nucleus similar to tic and flutter. Noise production may also depend on the presence of a stomach of the right shape and in the right position. The gas bubble is pushed well below the oesophago-gastric junction but is not eructated, so that an additional requirement may be a high cardiac sphincter tone.

The mechanics of noise production was not understood in the first patient, for whom no treatment was offered and we have lost contact. Explanation of the mechanism has enabled one patient to control the noise production. One patient had a left phrenic crush by Mr Norman Tanner which at least temporarily stopped the noise.

The description of the syndrome will be illustrated by audio tape recordings and cineradiology.

Thanks are due to Dr Avery Jones and Mr Norman Tanner who allowed us to see the patients.

\section{GASTRIC EMPTYING IN PATIENTS WITH POST-VAGOTOMY DIARRHOEA}

J. D. GEORGE, A. M. CONNELL, AND T. KENNEDY (Department of Surgery, Royal Victoria Hospital, Belfast) A change in bowel habit is not uncommon after the operation of vagotomy plus drainage and a significant number of patients develop troublesome diarrhoea. This diarrhoea has been variously attributed to denervation of the small bowel, to pancreatic insufficiency, and to intestinal infection.

In this investigation the rate of gastric emptying of a fluid test meal has been measured in patients before and after vagotomy and pyloroplasty. The emptying time has been measured using the double-sampling test meal. A very significant increase in the rate of emptying occurs after the operation.

Gastric emptying has been examined in a group of patients with diarrhoea one year after operation and compared with patients who had no change in their bowel function. The patients with persistent diarrhoea evacuated the fluid meal significantly faster than the patients with no change in bowel habit. Diarrhoea was noted in some patients after selective vagotomy and pyloroplasty; the rate of emptying in these patients was also significantly faster than the rate in symptom-free patients.

\section{GASTRIC ACID SECRETION IN RESPONSE TO A LACK OF METABOLIZABLE GLUCOSE}

D. G. COLIN-JONES AND R. L. HIMSWORTH (University College Hospital Medical School, London) introduced by J. E. Lennard-Jones. The non-metabolizable hexose, 3-O-methylglucose, has been used to investigate the mechanism which determines the release of acid during insulin-induced hypoglycaemia. This substance is known to compete with D-glucose for the glucose transfer system into the brain, ${ }^{1}$ and in the presence of a high plasma concentration this competition provokes the release of adrenaline, probably by affecting a central receptor. ${ }^{2}$ 3-O-methylglucose is biochemically inert and, unlike 2-deoxyglucose, cannot be phosphorylated and does not act as an intracellular inhibitor of glucose metabolism. The secretion of acid from the stomach of fasting rats during an hour's infusion of 3-O-methylglucose was studied by a modification of the technique of Ghosh and Schild, ${ }^{3}$ adrenaline release being prevented by denervation of the adrenal medulla. This infusion resulted in a marked and sustained rise in acid output, which could be abruptly terminated either by cutting the vagi or by the administration of sufficient glucose. In a number of separate experiments the onset of acid response was correlated with the plasma glucose and 3-O-methylglucose concentration, and the ratio of glucose to total sugar (glucose $+3-O$-methylglucose) was constant at the onset of acid secretion over a wide range of plasma glucose levels. These results show that the vagally mediated acid secretion in response to hypoglycaemia is dependent, not upon the blood or plasma glucose concentration itself, but upon the availability of metabolizable glucose to the central nervous system.

${ }^{1}$ Agnew, W. F., and Crone, C. (1967). Acta physiol. scand., 70, 168175.

'Himsworth, R. L. (1968). J. Physiol. (Lond.), 198, 451-477.

${ }^{3}$ Ghosh, M. N., and Schild, H. O. (1958). Brit. J. Pharmacol., 13, 54-61.

SIGNIFICANCE OF 'EARLY' AND 'LATE' GASTRIC SECRETORY RESPONSES TO INSULIN

JOHN SPENCER, R. A. PAYNE, G. P. BURNS, F. C. Y. CHENG, AND ALAN G. COX (Department of Surgery, Royal Postgraduate Medical School, London) When the gastric acid secretory response to insulin hypoglycaemia occurs more than 45 minutes after the injection of insulin, the response has been described as being 'late positive' (Ross and Kay, 1964). ${ }^{1}$ It has been suggested that a late positive response in patients after vagotomy for duodenal ulcer indicates a degree of gastric denervation adequate to prevent recurrent ulceration. 
In this paper are reported the results of insulin tests in 100 patients with duodenal ulcer. Although none had undergone vagotomy, $40 \%$ had late positive responses. Doubt is therefore cast on the hypothesis that such responses after operation indicate adequate vagotomy. This view is supported by a recent report that the incidence of recurrent ulceration in patients with late responses is as high as $24 \%$ (Johnston, Thomas, Checketts, and Duthie, 1967). ${ }^{2}$

The pattern of insulin-induced acid secretion was compared in those with early and those with late responses. There was no significant difference in mean peak acid concentrations or outputs in the two groups. When the time taken to achieve peak acid concentrations was plotted for all subjects, a normal distribution was found. The timing of the response to insulin is probably a random phenomenon independent of other secretory characteristics. It may therefore be of little prognostic value after operation.

'Ross, B., and Kay, A. W. (1964). Gastroenterology, 46, 379.

2Johnston, D., Thomas, D. G., Checketts, R. G., and Duthie, H. L. (1967). Brit. J. Surg., 54, 831.

\section{IS SELECTIVE VAGOTOMY SELECTIVE?}

J. TINKER, T. R. LAWSON, AND ALAN G. COX (Departments of Surgery and Radiology, Royal Postgraduate Medical School, London) A method is needed to test whether preservation of extragastric branches of the vagus has been successful in patients after selective vagotomy. This study was initiated in an attempt to establish such a method and was based upon radiological evaluation of changes in the size of the gall bladder. A standardized technique of cholecystography was employed throughout.

In 10 control subjects (with intact vagi) insulin hypoglycaemia caused a mean reduction in gall bladder size of $27.2 \%$. This contractile response was absent in five patients after truncal vagotomy and also in five patients after selective vagotomy, suggesting that both varieties of vagotomy resulted in denervation of the gall bladder.

To test the possibility that the gall bladders of patients after selective vagotomy were denervated, Cannon's Law (1949) ${ }^{1}$ was applied. Cannon's Law states that denervated organs are 'supersensitive', ie, they respond to subthreshold stimuli which are too small to evoke a response in normally innervated organs.

Studies with carbachol were carried out in 10 control subjects to ascertain a suitable subthreshold dose. Carbachol, $75 \mu \mathrm{g}$, caused no contraction of the gall bladder in all 10. The same dose of carbachol did cause contraction of the gall bladder in 10 patients after truncal vagotomy and in 10 after selective vagotomy; in the former the mean reduction in gall bladder size was $45 \%$ and in the latter $35.6 \%$. This difference was not statistically significant. The gall bladders of patients after selective vagotomy were therefore 'supersensitive' and, according to Cannon's Law, denervated.

These findings, which will be discussed, suggest (1) that the concept of supersensitivity requires re-evaluation, or (2) that the contractile responses of the gall bladder are not under direct control of the vagus, or (3) that selective vagotomy does not preserve normal gall bladder function.

'Cannon, W. B., and Rosenblueth, A. (1949). The Supersensitivity of Denervated Structures, p. 186. Macmillan, New York.

PEPTIC ULCER SURGERY IN RELATION TO THE PSYCHOLOGICAL STATUS OF THE PATIENT

W. P. SMALL, E. L. CAY, P. DUGARD, W. SIRCUS, C. W. A. FALCONER, A. N. SMITH, J. P. A. MCMANUS, AND SIR JOHN BRUCE (Gastro-Intestinal Unit, Western General Hospital, M.R.C. Unit for Research into the Epidemiology of Psychiatric Illness, and the University Department of Statistics, Edinburgh). For success in the treatment of peptic ulcer it is said that early operation is inadvisable. Many surgeons and more physicians claim that young patients do badly and that patients with a short history fail to adapt postoperatively, becoming easily dissatisfied and complaining unduly of minor symptoms. According to this view, operation is justified only after the endurance of symptoms for many years, and thus the patient must 'earn' his operation. Implicit in the arguments in favour of such a policy is the belief that operation should be avoided in the psychiatrically unstable person. But does postponement of operation improve the result and is the outcome in young patients less satisfactory than in their seniors? Also does delay in operation exclude the psychiatrically unsuitable patient and does such a patient have a poor physical outcome?

In an attempt to answer these questions two groups of patients were studied. In the first, the results of operation in 147 patients who had undergone surgical treatment for duodenal ulcer not less than five years before were assessed and their outcome related to the length of history before operation, to the age of the patient at operation, and to the type of operation employed. Neither length of history nor age at operation was shown to influence the result.

In the second group, the results of surgery in 98 patients who underwent operation 10 years after the first group were examined over a period of two and a half years.

At initial assessment $65 \%$ of the group were psychiatrically ill. Those patients who had psychiatric symptoms did not undergo operation sooner than those without psychiatric symptoms. Seventy per cent of the psychiatrically ill patients had a good physical outcome.

Psychiatrically, a third of the patients with preoperative psychiatric symptoms improved after surgery. Of the others some deteriorated, but surgery could not be blamed for this worsening of the psychiatric state because in a comparable group of medically treated patients there was a similar deterioration over the same period of follow-up.

There was no evidence that successful surgery is followed by the formation of new psychiatric symptoms. On the contrary, physical success correlated highly with psychiatric success.

The practical significance of the findings is that a combined physical and psychiatric assessment of the patient with chronic peptic ulcer is necessary if the 
highest proportion of good results in the greatest number of patients is to be obtained.

COMPARISON OF PYLOROPLASTY AND GASTROJEJUNOSTOMY

F. KENNEDY, I. E. GILLESPIE, AND A. W. KAY (University Department of Surgery, Western Infirmary, Glasgow) Since 1966 the members of our department have conducted a random trial of pyloroplasty and gastrojejunostomy used as drainage procedures to accompany truncal vagotomy in the elective surgical treatment of chronic duodenal ulcer. In spite of theoretical considerations we did not know whether one possesses distinct advantages over the other. All pre- and postoperative clinical, laboratory, and other data, and the operative details, were recorded on forms designed for computer processing, as part of a more comprehensive scheme.

Analyses are presented of the first 200 patients admitted to the trial. First, the preoperative findings in the two groups of 100 pyloroplasties and 100 gastrojejunostomies were comparable with regard to sex distribution, mean age, mean length of history, previous complications, acid secretion, and other factors. Postoperatively there were no significant differences between the two procedures with regard to acid secretory responses to maximal stimulation, or to fixed dosage of insulin. No clear difference in the overall incidence of postoperative sequelae emerged, although some slight variation in the nature of the sequelae and their management was noted. Other factors assessed include early postoperative complications, weight changes, bowel habit, and the relationship between psychological scoring and postoperative progress.

USE OF INTRAVENOUS VITAMIN $D_{3}$ IN THE DETECTION OF VITAMIN D DEFICIENCY

H. C. WHITTLE, A. A. BLAIR, G. NEALE, N. THALASSINOS, AND G. R. THOMPSON (Department of Medicine, Royal Postgraduate Medical School, London) A rise in serum phosphate after intravenous vitamin D coincides with histological improvement in osteomalacia (Bordier, Hioco, and Hepner, 1968). ${ }^{1}$ This observation has been used in the present study to detect subclinical vitamin D deficiency.

Five healthy control subjects, all with normal serum vitamin D-like activity on bioassay, were given $1 \mathrm{mg}$ of vitamin $\mathbf{D}_{3}$ in propylene glycol intravenously. Their serum phosphate during the subsequent five days (mean \pm 2 S.D.) did not vary by more than $\pm 25 \%$ of the pre-treatment level. Intravenous vitamin $\mathrm{D}$ was also administered to 43 consecutive inpatients, mostly with gastrointestinal disorders. These patients were then divided into two groups, according to whether or not their mean serum phosphate on the fourth and fifth days after vitamin $\mathrm{D}$ increased $>25 \%$ above the mean of two basal values.

Eleven patients showed a positive response. This group comprised six postgastrectomy subjects, one with adult coeliac disease, one with intestinal resection, one with alcoholic cirrhosis, and two patients with a low dietary intake of vitamin $D$. The basal serum values of this group (mean \pm S.D.) were calcium $4 \cdot 6 \pm 0.3$, phosphate $1.5 \pm 0.3 \mathrm{~m}$-equiv/l. and alkaline phosphatase $15 \pm 6$ K.A. units. Four patients in whom serum vitamin D-like activity was measured had subnormal levels. After vitamin $\mathrm{D}$ the serum phosphate rose to $2 \cdot 2 \pm \mathbf{0 . 3}$ m-equiv/l. ( $p<0.001$ ). The remaining 32 patients showed no response; all were found to have normal serum calcium, phosphate, and alkaline phosphatase both before and after vitamin $\mathbf{D}$.

These results suggest that a significant rise in serum phosphate after $1 \mathrm{mg}$ of intravenous vitamin $\mathrm{D}_{3}$ provides a sensitive and convenient index of vitamin $D$ deficiency. The possible mechanisms involved will be discussed in relation to urinary phosphate excretion.

${ }^{1}$ Bordier, P., Hioco, D., and Hepner, G. (1968). Abstracts of second Annual Meeting, European Society for Clinical Investigation, p. 13.

\section{SMALL INTESTINAL EXFOLIATIVE CYTOLOGY}

I. J. PINK, D. N. CROFT, AND B. CREAMER (St. Thomas' Hospital, London) There is little information on the cellular content of the small intestinal lumen. Cells from specimens obtained by washing the normal small intestine of $\operatorname{man}^{1}$ and rat $^{2}$ have been stained and examined under the light microscope. Despite the fact that the washing methods were designed to collect cells that had recently exfoliated from the small intestinal mucosa, the cells were found to be in various states of disintegration, making it impossible to identify cell types. As it has been claimed that deoxyribonucleic acid (DNA) measured in these specimens arose predominantly from small intestinal epithelial cells, it was necessary to find a method of identifying the cells in the specimens.

The brush border of epithelial cells can be readily seen by electron microscopy, and it is resistant to processes that damage the rest of the cell. ${ }^{3}$ Cells with brush borders were easily recognized in specimens obtained by the saline washing method, but were not present in specimens obtained by a perfusion method. The proportion of epithelial to total cells was estimated, and the data confirmed that the majority of the cells in the washings were small intestinal absorptive cells. Other cells were identified as lymphocytes.

Thus, in the normal small intestine of man, surface epithelial cells are shed into the lumen in a relatively intact state. They are then rapidly destroyed.

${ }^{1}$ Croft, D. N., Loehry, C. A., Taylor, J. F. N., and Cole, J. (1968). Lancet, $2,70$.

${ }^{2}$ Loehry, C. A., Croft, D. N., Singh, K., and Creamer, B. Gut, in press.

${ }^{3}$ Miller, D., and Crane, R. K. (1961). Ann. Biochem., 2, 284.

METABOLISM OF DIETARY NITROGEN IN RATS WITH SMALL INTESTINAL BLIND LOOPS

B. Miller, S. TABAQChali, AND G. NEALE (Royal Postgraduate Medical School, London) Increased bacterial proliferation within the small bowel of rats with surgically created blind loops leads to impaired absorption of fat and vitamin $B_{12}$ (Donaldson, 1962,1 1965'). In this 
paper we report our observations of the effect of the blind loop syndrome on the metabolism of several dietary nitrogenous and vegetable substances.

Self-filling blind loops of jejunum 5 to $8 \mathrm{~cm}$ long were constructed as close as possible to the duodeno-jejunal flexure in Wistar rats weighing 100 to $150 \mathrm{~g}$. Nineteen blind loop rats and 10 sham-operated control rats were studied for at least six months after operation. The blind loop animals grew more slowly and absorbed fat less well than the controls. The urinary excretion of the following substances by the two groups of animals were compared: indoxyl sulphate and indolyl-3-acetic acid (derived from tryptophan), piperidine (from ornithine and arginine), pyrrolidine (from lysine), other amines (from glycine, sarcosine and creatine), hippuric acid (from vegetable products and phenylalanine), volatile phenols (from tyrosine and phenylalanine) and phenolic acids (from vegetable acids). Blind loop animals excreted much greater quantities of indoxyl sulphate, hippuric acid and volatile phenols than control animals. In addition, piperidine and pyrrolidine were detected in the urine of rats with blind loops but not in control animals.

The differences between the two groups of animals disappeared almost completely when the rats were fed either neomycin or lincomycin. The metabolic effects of the blind loop syndrome will be discussed in the light of changes demonstrated in the bacterial flora of the small intestine.

'Donaldson, R. M. (1962). Gastroenterology, 43, 271.

2 - (1965). J. clin. Invest., 44, 1815.

MICROANATOMY OF THE MUSCULAR WALL OF THE HUMAN COLON

J. L. PACE (Royal University of Malta, Malta) introduced by J. E. Lennard-Jones. The organization of the muscular wall of the human colon has been investigated by microdissection techniques. Postmortem material was used, some of the specimens dissected being given preliminary treatment with collagenase.

The two muscle coats were found to be organized on similar structural patterns; in both layers, the muscle was divided by connective tissue septa into muscle bands which interlinked to form expandable meshworks.

In the circular layer, each band was on an average $1 \mathrm{~mm}$ wide and consisted of about four to six fasciculi of the order of $100 \mu$. The bands were continuous beneath the taeniae.

In the longitudinal layer the muscle bands were smaller. The taeniae were divided into bands only in their outer part, the inner region consisting of a mosaic of cell groups. The intertaenial longitudinal muscle, also divided into bands, formed a thin but complete layer.

The two muscle coats were found to be intimately bound together both by muscular and connective tissue connexions (Pace). ${ }^{1}$ Longitudinal muscle fibres near the borders of the taeniae were found to change direction suddenly and, interlacing with the more peripheral longitudinal fibres, to course towards and fuse with the main circular muscle layer.

With distension, the bands of the circular layer became rounder and more spaced and their fasciculi less obvious.
In the longitudinal layer, the intertaenial bands became flatter and wider apart; while in the taeniae, the fibres of the inner region disappeared, as if pulled outwards through their connection with the circular muscle, so that the connective tissue septa came to lie adjacent to the circular layer.

The organization of both muscle layers into expandable meshworks readily adapts them to an increase in the length and circumference of the colon while preserving their mechanical strength and functional structure.

'Pace, J. L. (1968). J. Anat., 103, 289.

CHANGES IN THE HAUSTRAL PATTERN IN DIVERTICULAR DISEASE AND THE IRRITABLE COLON SYNDROME

M. CHAPMAN AND J. J. MISIEWICZ (The Department of Radiology and the Research Department, St. Mark's Hospital, London) Diverticular disease and irritable colon syndrome are associated with abnormalities of motility, but virtually all existing studies have been confined to the sigmoid and rectum. This communication describes studies on the extent of involvement of the proximal colon in these conditions.

The number of haustral folds present on doublecontrast barium enema films of the ascending, transverse, and descending colon was counted, and the results were expressed by calculating the number of haustra $/ \mathrm{cm}$ length of colon (haustral index).

Films of 34 patients with left-sided diverticular disease, 30 patients with extensive diverticular disease, 31 with the irritable colon were analysed, and compared with films of 35 patients with small colonic polyps, who served as controls.

Patients with diverticula confined to the left colon had a significantly higher mean haustral index than the controls in all parts of the large bowel that were studied, and similar changes were found in extensive diverticular disease. In the irritable colon syndrome group there was a significant rise in the number of haustra in the transverse colon. There was no correlation between haustral index and age in any of the four groups.

The results indicate that diverticular disease confined to the sigmoid may be associated with changes affecting the whole bowel. Although the incidence of diverticular disease is known to increase with age, ageing was not accompanied by increased numbers of haustral folds. This suggests that the factor causing the observed rise in haustral index was diverticular disease rather than the age of the patient.

PROPULSION AND RETROPULSION IN THE HUMAN COLON DEMONSTRATED BY TIME-LAPSE CINEFLUOROGRAPHY

J. A. RITCHIE, S. C. TRUELOVE, AND G. M. ARDRAN (Nuffield Department of Clinical Medicine and Nuffield Institute for Medical Research, Oxford) The possibility that normal propulsive movements of the colon might travel as slowly as 1 to $10 \mathrm{~cm} / \mathrm{min}$ prompted us to study the human colon by time-lapse cinefluorography. Each subject was given $100 \mathrm{ml}$ of a barium suspension by mouth 12 hours before the period of observation. Cine films were exposed at one frame per minute for one or two hours at a time. 
A large number of studies using this method have shown that movements of the colon do occur at a slow rate and that some of these slow movements may cause a progressive shift of the contents in either direction over the course of many minutes.

Two examples of such observations will be demonstrated. The first film illustrates a typical form of mass propulsion in the transverse and descending colon; this took 12 minutes to traverse about $60 \mathrm{~cm}$ of gut that had temporarily lost its haustral pattern. The second film shows retropulsion throughout the distal half of the bowel with the contents of the rectum and sigmoid colon being transported up towards the splenic flexure by a series of adoral progressive movements at a rate of 0.5 to $1.0 \mathrm{~cm} / \mathrm{min}$. These appear to represent a type of retroperistalsis because a simultaneous intraluminal pressure record demonstrates an advancing ring contraction of the gut wall preceded by a zone of relaxation.

\section{CORTICOSTEROIDS IN CROHN'S DISEASE}

G. M. ROBERTS AND J. M. NAISH (Department of Gastroenterology, Frenchay Hospital, Bristol) Until 1966, when Jones and Lennard-Jones ${ }^{1}$ reported their findings in 30 patients, few studies had been carried out on the value of corticosteroids in Crohn's disease.

In the present retrospective study of 76 patients with Crohn's disease seen at Frenchay Hospital, Bristol, between 1958 and 1967, 53 patients were given steroids during the course of management (49 of these had oral prednisone). The disease had been diagnosed on clinical and radiological grounds, with histological confirmation in 35 cases, and typical laparotomy appearances in a further 14.

It was found that patients with diffuse involvement of the gastrointestinal tract, with no radiological evidence of intestinal lumen narrowing at presentation, did well on steroids. Prolonged treatment was necessary, and one-third tended to relapse when treatment was withdrawn.

Preoperative steroids, despite failure to impede the progress of the disease towards intestinal narrowing, appeared to reduce the recurrence rate after surgery.

Corticosteroids were of little advantage if patients had persistent ill health immediately after surgery. All required further operations.

Steroids were valuable for disease recurring some months after surgery; of 25 such patients given steroids, only five required further operations.

There were a few difficult and undesirable side effects with full dosage and these are described; maintenance doses were of the order of $5 \mathrm{mg}$ to $10 \mathrm{mg}$ of prednisone.

Malabsorption occurred despite treatment with steroids.

Postoperative progress did not appear to be delayed in those treated with steroids up to the time of operation.

' Jones, J. H., and Lennard-Jones, J. E. (1966). Gut, 7, 181.

MECHANISM BY WHICH FAT INHIBITS GASTRIC ACID SECRETION

G. GILlESPIE, B. S. BEDI, H. T. DEBAS, AND I. E. GILLESPIE (University Department of Surgery, Western Infirmary,
Glasgow) Fat coming in contact with the mucosa of the upper small intestine is known to exert an inhibitory influence on gastric acid responses. Evidence from transplanted pouch experiments suggests that this inhibition is humorally mediated, and the name 'enterogastrone' has been proposed for the inhibitor substance.'

It has been suggested that 'enterogastrone' acts by preventing the release of gastrin from the pyloric antrum. ${ }^{2}$ On the other hand, previous experiments in our laboratory demonstrated some inhibition of gastric pouch responses to crude gastrin extracts, suggesting an inhibitor action against circulating gastrin. In the present experiments the effectiveness of fat in the upper small intestine was compared against both endogenously released gastrin, and injections of either pure gastrin extract, or the synthetic pentapeptide, pentagastrin.

Dogs, each with a vagally innervated pouch of the pyloric antrum, and in addition a separated, Heidenhaintype fundic pouch were used. Matched Heidenhain pouch acid responses were first obtained to either irrigation of the antral pouch with acetylcholine, or injected gastrin or pentagastrin. Then $50 \mathrm{ml}$ of a commercial corn oil was fed to the dogs over a 15-minute period. The inhibition observed after feeding the corn oil was equal, both in degree and duration, against both the endogenous and exogenous gastrin stimulation. It was therefore concluded that the humoral agent released by the fat acts predominantly, or solely, by inactivating circulating gastrin, rather than by preventing gastrin release from the pyloric antrum.

No significant inhibition of matched histamine responses was observed on giving the oil.

${ }^{1}$ Kosaka, T., and Lim, R. K. S. (1930). Demonstration of the humoral agent in fat inhibition of gastric secretion. Proc. Soc. Exp. Biol. (N.Y.), 27, 890-891.

${ }^{2}$ Gregory, R. A., and Tracy, H. J. (1959). The action of enterogastrone on gastric secretion. J. Physiol. (Lond.), 149, 58-59p.

EFFECT OF BILE SALTS ON ANTRAL GASTRIN RELEASE

B. S. BEDI, G. GILLESPIE, AND I. E. GILLESPIE (University Department of Surgery, Western Infirmary, Glasgow) The exclusion of bile from the intestine has been found to diminish the effectiveness of the stimulation of gastric acid secretion arising from the presence of food in the small intestine. ${ }^{1}$ It is most likely that the bile salts are the fraction which facilitates the intestinal phase of gastric secretion, and there is good evidence that this latter is mediated by a humoral mechanism. ${ }^{2}$ The possibility also arises that the humoral agent arising from the small intestine mucosa may either be gastrin or a substance closely related to it.

The present study was therefore designed to determine what effects the local application of bile salt solutions might have on the capacity of the isolated pyloric antrum to release gastrin. Dogs, each with a vagally innervated pouch of the pyloric antrum, separated from the fundus by a double mucosal septum, and in addition a vagally denervated Heidenhain-type fundic pouch, were used. Gastrin release from the antral pouches was stimulated by the local irrigation of varying strengths of acetylcholine solution, with $p \mathbf{H}$ adjusted to alkaline values. Sodium taurocholate, and glycocholate, in concentra- 
tions ranging up to, but not greater than those found in gall bladder bile were added to the antral pouch irrigation solutions.

Potent stimulation of antral gastrin release was found from bile salt solutions alone, and serial dilutions demonstrated that this property persisted at very low concentrations. The combination of near threshold concentrations of bile salts and/or acetylcholine showed some degree of additive effects.

The results of the present study suggest that bile regurgitation into the antrum may be responsible for a possibly significant degree of gastric acid stimulation.

\footnotetext{
${ }^{1}$ Nahrwold, D. L., and Grossman, M. I. (1967). Effect of exclusion of bile from the intestine on gastric acid secretion. Gastroenterology, 52, 667-669.

${ }^{2}$ Sircus, W. (1953). The intestinal phase of gastric secretion. Quart. J. exp. Physiol., 38, 91-100.
}

INCREASED REFLUX OF BILE INTO THE STOMACH IN GASTRIC ULCER

J. RHODES, D. E. BARNARDO, S. F. PHILLIPS, R. A. ROVELSTAD, AND A. F. HOFMANN (Mayo Clinic, Rochester, Minnesota, $U S A)$ Since bile salts damage the gastric mucosa, bile reflux may be important in the pathogenesis or perpetuation of gastric ulcer. We therefore compared the concentration of bile salts in the fasting gastric content and after food in 10 gastric ulcer (GU) and 10 controls (N) matched for age and sex.

Patients had symptoms and ulceration on the lesser curvature proximal to the antrum. The bile salt pool was labelled with ${ }^{14} \mathrm{C}$ chenodeoxycholic acid $(8$ to $30 \mu \mathrm{c})$. A nasogastric tube was positioned by $x$-ray in the proximal antrum and samples obtained every 15 minutes for one hour fasting and three hours after either two or three standard liquid meals which contained polyethylene glycol (PEG). The radioactivity of all samples was measured, bile salt concentrations were determined enzymatically in two, and specific activity was calculated.

After food there was a significant difference between normal and gastric ulcer. Bile salt concentrations were significantly greater in ulcer after food. Mean (N:0.058 \pm 0.011; GU: $0.78 \pm 0.33 \mathrm{mM}(\mathrm{p}<0.01)$; maximum concentration $(\mathrm{N}: 0.16 \pm 0.33 ; \mathrm{GU}: 5 \cdot 3 \pm 2 \cdot 6 \mathrm{mM}$ $(\mathrm{p}<0.01)$ occurred within two and a half hours. Ultracentrifugation studies established that the bile salts were largely in solution. PEG studies showed progressive dilution of the meal and changes in bile salt concentration were independent. The amount of reflux was similar for all meals in the same subject. There was no significant difference between the two groups in the concentration of bile salts in fasting contents.

The study was repeated two to five months later in four patients after the ulcer had healed; in three, bile salt concentrations returned to the normal range.

A method has been developed to quantify bile reflux into the stomach. After food, patients with active gastric ulcer have greater reflux of bile salts than normal. The reflux may be secondary to the ulcer, or the primary mechanism and then represent an initiating or perpetuating factor in ulceration.
EFFECT OF PANCREATIC INSUFFICIENCY AND INTESTINAL LACTASE DEFICIENCY ON THE GASTRIC EMPTYING OF STARCH AND LACTOSE

C. N. MALlinson (Guy's Hospital, London) Glucose in test meals slows gastric emptying in direct relation to the osmolarity of the test meal given. In spite of their great difference in osmolarity, isocaloric solutions of starch and glucose have been found to slow gastric emptying to the same extent. ${ }^{1}$ Similarly lactose solutions slow emptying almost as effectively as isocaloric meals containing a mixture of glucose and galactose. ${ }^{2}$ Since intragastric digestion of starch or lactose did not occur during these experiments, it has been suggested that complete hydrolysis of starch and lactose occurs before a postpyloric osmoreceptor is stimulated and slows gastric emptying.

Ten patients with pancreatic disease have been studied. Four of these had steatorrhoea and showed marked reduction or absence of the slowing effect of starch. Three patients without steatorrhoea showed a significant reduction of the slowing effect of starch, while three showed the normal effect.

In one patient with intestinal lactase deficiency the slowing effect of lactose was absent.

It appears that deficiency of amylase or lactase is associated with rapid emptying of starch and lactose loads into the small intestine. Thus an enzyme system which is already subnormal is faced with a load of substrate delivered with abnormal rapidity.

The diagnostic usefulness of these findings is discussed.

${ }^{1}$ Hunt, J. N. (1960). J. Physiol. (Lond.), 154, 270-276.

${ }^{2}$ Elias, E., Gibson, G. J., Greenwood, L. F., Hunt, J. N., and Tripp, J. H. (1968). Ibid., 194, 317-326.

DIAGNOSIS AND MANAGEMENT OF NON-GANGRENOUS ISCHAEMIC COLITIS

A. R. BROWN (St. James' Hospital, Balham) introduced by Norman C. Tanner. Ischaemic colitis has only recently come to be recognized as a disease entity. The term was first used to describe changes sometimes observed in the colon after aortic surgery, ${ }^{1}$ but it has since been extended to include all forms of colonic disease with an ischaemic origin. ${ }^{2}$

On the basis of our own observations and the reports of others a simple clinical classification of ischaemic colitis into (1) gangrenous, and (2) non-gangrenous is proposed. Gangrenous ischaemic colitis is a serious condition with a high mortality, but it is fortunately rare.

This paper presents the clinical, radiological and pathological findings in 14 patients with non-gangrenous ischaemic colitis.

The mode of presentation of the condition is characteristic: the patient is seized with lower or left-sided abdominal pain, sometimes accompanied by vomiting; this is followed shortly by diarrhoea and rectal bleeding. There are few physical signs but some patients gave signs of intestinal obstruction. The attack is self-limiting, its severity and duration being unrelated to the length of colon involved. The diagnosis is confirmed by barium enema. 
There were no resections performed during the acute episode in this group. Nine patients were managed conservatively and some have remained well for nearly three years. Five patients had resections done as interval procedures. The resected specimens all showed widening of the submucosa, superficial mucosal ulceration, and marked narrowing of the lumen.

Twelve of these patients presented in a single hospital in the space of two years. Non-gangrenous ischaemic colitis is thus a relatively common condition. Although the long-term prognosis is as yet uncertain, the pathological changes are to some extent reversible and a considerable degree of functional and radiological recovery is to be expected after the acute episode. The management should therefore be conservative in the first instance. Resection is only necessary for those patients who develop extensive stricturing of the affected colon.

${ }^{1}$ Birnbaum, W., Rudy, L., and Wylie, E. J. (1964). Dis. Colon Rect., 7 , 293.

${ }^{2}$ Marston, A., Pheils, M. T., Thomas, M. L., and Morson, B. C. (1966). Gut, 7, 1 .

\section{The October 1968 Issue}

\section{THE OCTOBER 1968 ISSUE CONTAINS THE FOLLOWING PAPERS}

\section{Signposts}

Diverticular disease of the colon: A 1968 view IFOR WILLIAMS

Colonic motor activity and bowel function. Part II: Distribution and incidence of motor activity at rest and after food and carbachol J. A. RITCHIE

Study of large bowel peristalsis J. D. HARDCASTLE and c. V. MANN

Studies of intestinal fermentation in ulcerative colitis. R. D. MONTGOMERY, A. C. FRAZER, CATHRYN HOOD, J. M. GOODHART, M. R. HOLLAND, and R. SCHNEIDER

Amino acid incorporation into proteins of human normal and ulcerative colitis colonic mucosa MARTIN BROTMAN

An evaluation of perfusion techniques in the study of water and electrolyte absorption in man: the problem of endogenous secretions G. E. SLADEN and A. M. DAWSON

Biliary excretion of antibiotics in man G. ACOCELLA, $R$. MATTIUSSI, F. B. NICOLIS, R. PALlANZA, and L. T. TENCONI

A study of human gall bladder muscle in vitro A. J. MACK and J. K. TODD

Changes in the ultrastructure of gall bladder epithelium in rabbits with experimental gallstones A. F. HAYWARD, J. W. FRESTON, and I. A. D. BOUCHIER

Effects of ethyl alcohol on sphincteric resistance at the choledocho-duodenal junction in man R. C. PIROLA and A. E. DAVIS

Effect of sodium desoxycholate on the intestinal absorption and lymphatic transport of oleic acid in the bile fistula rat N. D. GALlaGHer, J. P. W. WeBB, and A. M. DAWSON
Macroglobulinaemia and steatorrhoea J. BRADLEY, C. F. HAWKINS, D. S. ROWE, and D. R. STANWORTH

Primary lymphadenopathy complicating idiopathic steatorrhoea R. WHITEHEAD

Postgastrectomy malnutrition H. S. HILLMAN

B-Glucuronidase activity of gastric juice in gastric carcinoma R. I. RUSSELL and C. WATTS

Clinical evaluation of three long-acting anticholinergic compounds MICHAEL D. KAYE, JOHN RHODES, and PETER M. SWEETNAM

Calcium absorption in the normal, bile-duct ligated, and cirrhotic rat, with observations on the effect of long- and medium-chain triglycerides A. K. KEHAYOGLOU, H. S. WILLIAMS, W. F. WHIMSTER, and C. D. HOLDSWORTH

Vagal influence in gastric acid secretion in normals and in duodenal ulcer patients HARMIT SINGH, R. K. GOYAL, D. $S$. AHLUWALIA, and H. K. CHUTTANI

Coarse duodenal folds in patients with peptic ulcer J. RHODES, J. H. LAWRIE, and K. T. EVANS

Radiotelemetering studies of jejunal $p \mathbf{H}$ before and after vagotomy and pyloroplasty J. D. MAXWELL, W. C. WATSON, J. K. WATT, and A. FERGUSON

An infrared spectrophotometric method of estimating polyethylene glycol 4000 MARGARET $w$. DAVIES and R. SHIELDS

European Association for the Study of the Liver

Comment

Notes and activities

Copies are still available and may be obtained from the PUBLISHING MANAGER, BRITISH MEDICAL ASSOCIATION, TAVISTOCK SQUARE, W.C.1, price 18s. 6D. 